\title{
La recerca recent sobre jocs tradicionals i la seva aplicació en l'àmbit educatiu. El programa Els jocs en la història
}

\author{
Elena Espuny Arasa \\ Institut Ramon Muntaner \\ elena@irmu.org
}

Resum

Larticle parla de diverses jornades d'estudi sobre jocs tradicionals que, organitzades per l'Institut Ramon Muntaner juntament amb el Centre de Promoció de la Cultura Popular i Tradicional Catalana, han tingut lloc de manera anual i itinerant pels territoris de parla catalana. Aquestes jornades, que van iniciar el seu recorregut el 2006 en la Festcat d'Horta de Sant Joan, van desembocar en "Els jocs en la història", un programa d'impuls a la recerca i la difusió en temes relacionats amb els jocs tradicionals.

Bona part de les recerques i experiències d'aplicació presentades al llarg d'aquestes jornades han estat elaborades per docents, museus i entitats culturals, que han mostrat el joc com a recurs transversal en l'àmbit de l'educació infantil i primària $i$, en definitiva, han evidenciat el potencial formatiu del joc tradicional en l'àmbit escolar.

Paraules clau: Jocs tradicionals, recerca, educació, escola, centres d'estudi, museus.

\section{Abstract}

This article describes several symposia on traditional games organised by the Ramon Muntaner Institute in conjunction with the Centre for the Promotion of Catalan Popular and Traditional Culture. They have taken place annually in different places throughout the Catalan-speaking world. These symposia first began in 2006 at the Festcat in Horta de Sant Joan and developed into the "Games throughout History" programme, designed to promote research into and the dissemination of traditional games.

Much of the research and many of the experiences presented during the symposia have been carried out by teachers, museums and cultural organisations, and have shown that games are in general use throughout infant and primary education. In short, they have shown the educational potential of traditional games in schools.

Key words:Traditional games, research, education, school, study centres, museums.

\section{Introducció}

L'Institut Ramon Muntaner. Fundació dels Centres d'Estudi de Parla Catalana (IRMU), ubicat a Móra la Nova, treballa des del 2003 amb l'objectiu de donar suport i difondre els projectes d'investigació i de difusió cultural dels centres i instituts d'estudis dels territoris de parla catalana, fomentar el treball en xarxa i donar suport a la connexió entre els centres d’estudis i el món universitari.

Des del 2006, l'IRMU col-labora amb el Departament de Cultura de la Generalitat en la gestió de l'Inventari del Patrimoni Etnològic de Catalunya (IPEC), i en el foment de la recerca etnològica.

A instàncies del Centre de Promoció de la Cultura Popular i Tradicional Catalana - actual Direcció General de Cultura Popular i Tradici- 
onal-, l'IRMU va participar en el 10è. i l'11è. Curs de Jocs Tradicionals de la FESTCAT a Horta de Sant Joan, tot organitzant una jornada d'estudi sobre jocs tradicionals que formava part del curs. Així, el 2006 va tenir lloc a l'Ecomuseu dels Ports la "I Jornada sobre Recerca i Patrimoni Etnològic: Els Jocs Tradicionals" i el 2007 la "II Jornada sobre Recerca i Patrimoni Etnològic: Els jocs tradicionals i les noves tecnologies".

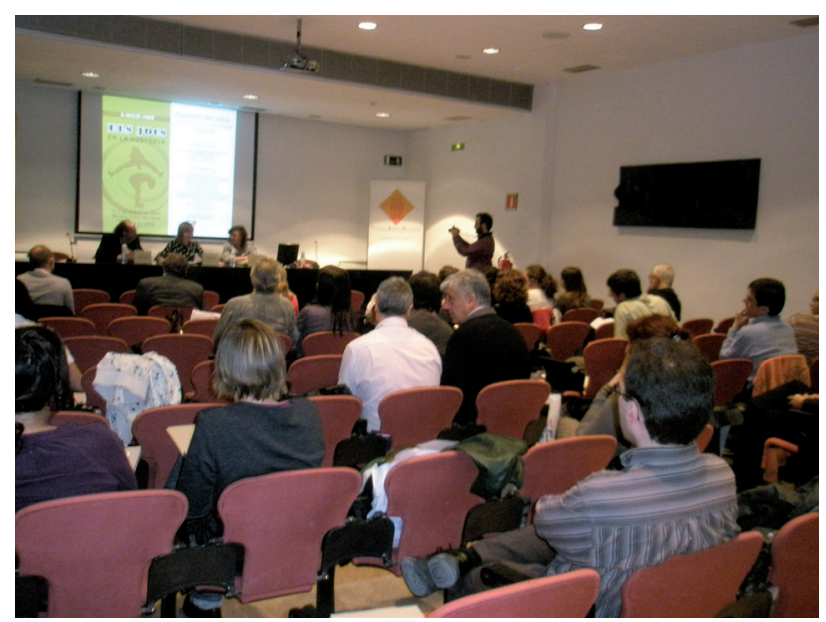

Jornada «Espais de joc: patrimoni, turisme i festa». Fons IRM. Tarragona, maig del 2009.

En vista del potencial que tenia la temàtica, es va decidir engegar "Els jocs en la història 20082012". Es tractava d'un programa que impulsava la recerca i la difusió de temes relacionats amb els jocs tradicionals, estructurat en quatre jornades d'estudi i un congrés de cloenda. Durant cinc anys, cada primavera "Els jocs en la història" va recórrer el territori català i va abordar els jocs tradicionals des d'enfocaments temàtics diferents.

Els objectius eren donar a conèixer la pràctica i la transmissió dels jocs en el temps, en els diversos territoris de parla catalana i en territoris propers; recollir i potenciar la recerca sobre els jocs tradicionals que es realitzava des dels centres d'estudis, universitats i museus; fomentar la creació d'un fòrum d'entitats, investigadors i docents interessats en l'anàlisi dels jocs tradicionals des de diferents enfocaments disciplinaris: antropològic, històric, sociològic, pedagògic, arqueològic, turístic, etc. i finalment facilitar l'aplicació a lensenyament formal i no formal dels resultats recollits en els estudis, a través de projectes educatius.

Els treballs presentats en cada jornada es van centrar en aspectes diferents dels jocs tradicionals tant d'infants com d'adults. Així, la primera jornada, titulada "Les societats a través del joc" (Tàrrega, 2008), va analitzar el joc com a manifestació sociocultural i com a element identificador i transmissor de valors, símbols i significats. La segona edició, "Espais de joc: patrimoni, turisme i festa" (Tarragona, 2009), es va centrar en la reflexió i les experiències envers els diferents espais del joc tradicional en la seva condició de patrimoni cultural i en el context del turisme i de la festa. El Museu del Joguet de Catalunya (Figueres) va albergar el 2010 la jornada "Cultura material i cultura immaterial en el joc", dedicada a l'anàlisi i la construcció del joguet i a la reflexió sobre els aspectes immaterials del joc, com ara els valors que transmet. "Els jocs i la interculturalitat (Berga, 2011) va estar la temàtica de la quarta jornada, que va fer aportacions a la següent pregunta: es pot fomentar la tolerància i el respecte a la diversitat a partir del joc tradicional?, tot reflexionant sobre quin paper ha tingut el joc en la història i quin té en l'actualitat com a recurs per a afavorir el coneixement, el respecte entre cultures i la cohesió social.

Recerques i experiències d'aplicació sobre jocs presentades des de o per a l'educació infantil i primària

Al llarg de les sis jornades i el congrés celebrats entre el 2006 i el 2012, s'han presentat cent trenta-sis treballs de recerca sobre jocs o experiències d'aplicació amb el joc com a fil conductor a través de ponències, comunicacions, pòsters, tallers, audiovisuals i exposicions. D’aquests, pràcticament la meitat corresponen a projectes duts a terme per professionals dels diversos nivells de l'ensenyament, tan reglat com no reglat. Aquestes intervencions han estat, d'una banda, explicacions d'activitats pràctiques que empren el joc com a recurs en l'àmbit educatiu i, d'una altra banda, reflexions sobre el paper formatiu del joc tradicional. 




Portada del programa de la jornada celebrada al maig del 2010, a Figueres. Fons IRM.

El gruix dels treballs han estat presentats per docents d'educació primària o per altres institucions i entitats que elaboren materials i activitats per a alumnes d'educació infantil i primària (com museus, camps d'aprenentatge, escoles autonòmiques de jocs, associacions culturals, empreses de turisme cultural o de lleure, etc.). Centrant-nos en aquests treballs, i sense ànim de ser exhaustius, a continuació en fem un repàs destacant-ne alguns.

En primer lloc, a les jornades hi hem pogut resseguir la petjada que ha deixat entre molts docents de les Terres de l'Ebre el "Curs de Jocs Tradicionals" de la FESTCAT que durant catorze anys s'ha celebrat a Horta de Sant Joan (Terra Alta). Molts d'ells han estat alumnes d'aquest curs. Això explica que centres com els que conformen la ZER Ports-Algars (Lourdes Rodriguez, etc.) o la ZER Terra Alta Centre duguin a terme, des de fa diversos anys, projectes educatius en què hi participen diverses àrees curriculars emprant el joc com a vehicle educatiu principal, que han explicat a les jornades. Aquesta petjada l'hem trobat també en escoles de comarques veïnes, on és palès l'interès per utilitzar els reculls de jocs tradicionals i aplicar-los a les etapes d'educació infantil i primària. Aquí, a la feina dels docents en actiu als seus centres mateix, s'hi afegeix la feina d'investigadors, docents i educadors que formen part d'un nombre destacable d'entitats culturals, des de les quals dissenyen i ofereixen projectes o materials educatius sobre jocs. Aquest és el cas de l'Associació Cultural "Lo Llaüt"1 (Ascó), l’Associació Cultural "Lo Rafal” (Alcanar), l'Associació Cultural del Matarranya (Calaceit), la Cia de Jocs l'ANÒNIMA, associació cultural, els Guies dels Ports (Arnes), l'Aula de Natura, artesania i tradicions (Arnes), l'Associació Cultural "La Riuada" (Móra d'Ebre) o el Centre d'Estudis de la Ribera d'Ebre.

D'altra banda, hem pogut escoltar reflexions de docents amb una llarga experiència en l'anàlisi, la recuperació i l'ús del joc tradicional, en el seu vessant material i immaterial, com les de Joan Sans Mercadal, Daniel Descomps, Biel Pubill, Miqui Giménez o M. Antònia Pujol. El mestre d'Alaior i autor de diverses publicacions sobre jocs menorquins Joan Sans ens ha parlat de la importància del joc en la infantesa per a la conformació del caràcter i per a la construcció de la intel-ligència emocional del futur adult. Daniel

1 En aquesta entitat cal resseguir la labor del Biel Pubill, mestre i professor d'Educació Física a l'IES de Flix, investigador sobre jocs, autor de diversos materials educatius que hi estan relacionats i codirector del "Curs de Jocs Tradicionals" de la FESTCAT d'Horta de Sant Joan durant diversos anys. http://bieljoc.blogspot.com; www.jocsanonima.wordpress.com ; 
Descomps, excatedràtic de l'Institut Universitari de Formació de Mestres de l'Aquitaine, actualment recorre les escoles i associacions culturals de França ensenyant als nens a construir-se les pròpies joguines amb els elements més propers de la natura ${ }^{2}$. Biel Pubill, mestre a Flix, és impulsor de molts projectes educatius, patrimonials, festius, culturals, esportius, etc. que empren el joc tradicional com a motor, com entre altres, el Tradijoc de la Ribera d'Ebre i la Terra Alta. Miqui Giménez, mestre i músic de Terrassa, ha evidenciat la funcionalitat del joc com a recurs d'integració, a casa nostra, de nens provinents de diferents cultures, a través d'experiències de recuperació dutes a terme al Pallars Sobirà. També llarga és l'experiència de M. Antònia Pujol, professora de l’Aula de Música Popular i Tradicional Catalana, així com la seva tasca en la recuperació

$2<$ www.jouet-rustique.blogspot.com>. de jocs tradicionals cantats o que utilitzen la música i la seva introducció en els currículums d'infantil i primària ${ }^{3}$. Tampoc no podem deixar de mencionar la tasca d'Àngel Gómez al capdavant de l'Escola Autonòmica de Jocs Tradicionals de València (Benissanó), des d’on s'impulsen projectes de jocs a les escoles del País Valencià, o la duta a terme des de fa anys per la "Federación Cántabra de Bolos" a les escoles de Cantàbria amb el projecte "Madera de ser", que treballa amb els nens la identitat i la cohesió social a través de les modalitats càntabres de bitlles.

La jornada "Els jocs i la interculturalitat" ha donat peu a l'exposició de molts estudis sobre la integració dels nens i joves nouvinguts i sobre la realitat social de partida, com és el cas del tre-

3 Busqué, Montserrat i Pujol, M. Antònia (1996): Ximic. Jocs tradicionals. Amalgama Edicions.

$4<$ www.maderadeser.com $>$.



Taller «Jocs de taula d’arreu del món». Fons IRM. Berga, abril del 2011. 
ball de camp fet per Cris Molins, antropòloga del Grup EMIGRA de la UAB, en què analitza com juguen i com no juguen els nens i nenes en els patis escolars de Catalunya ${ }^{5}$.

Per la seva part, els museus han tingut un important paper en la presentació de treballs de caire educatiu, sia perquè tenen joguets en les seves collleccions, sia perquè estudien el joc tradicional com a element social i lúdic del seu entorn, o àdhuc sia perquè empren el joc com a metodologia de transmissió del seu discurs museístic. Parlem d'equipaments que acullen grups d'escolars i que fan una tasca silenciosa, però valuosa, des l'educació no formal. De la vintena

5 Ponència de la jornada "Els jocs i la interculturalitat" (Berga, 2011): "El joc com a element inclusiu als patis escolars de Catalunya" http://grupsderecerca.uab.cat/emigra/content/cris-molins. Amb la mateixa temàtica, també cal esmentar l'article de Bianka Pires, "El pati escolar i la integració social d’alumnes estrangers", publicat al núm. 28 de la Revista d'etnologia de Catalunya (pàg. 84-95). llarga d'estudis i experiències pràctiques presentades, en podem destacar un projecte realitzat al llarg de dotze anys: "El joc tradicional al rodal d'Arbúcies", del Museu Etnològic del Montseny. (Foto 05) Es tracta de la documentació de més de tres-cents jocs i joguines tradicionals de la primera meitat del segle $\mathrm{xx}$ a la zona i la difusió dels resultats en un DVD interactiu, d'interès per als docents i extrapolable a qualsevol altre territori. També s'han presentat reculls o experiències de difusió de jocs del territori des del Museu Comarcal de l'Urgell, l'Ecomuseu de les Valls d'Àneu (Esterri d’Àneu), el Museo de Juegos Tradicionales de Campo (Osca), el Museu de les Terres de l'Ebre (Amposta), el Museu de Joguets i Autòmats de Verdú, etc. En relació amb els museus o equipaments patrimonials que utilitzen el joc com a eina de transmissió del seu missatge per a escolars que han presentat treballs, cal mencionar la Ciutadella Ibèrica de Calafell, el



Alumnes d'educació infantil i primària jugant a bitlles. Bolera Madera de Ser, Santander.

Foto: José A. Hoyos. Fons de la FCB, 2003. 
Museu de l'Esperanto (Subirats) o el Museu del Càntir d'Argentona, entre altres. Les eines d'ensenyament, en aquests casos, van des dels jocs de rol fins als jocs de carrer o de plaça, passant pels jocs de pistes i els jocs de taula.

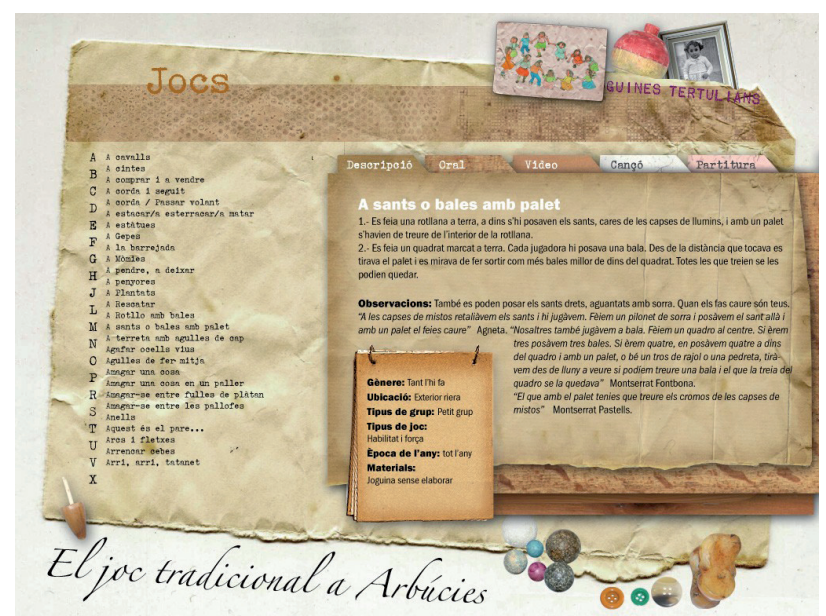

Fitxa de l'apartat de jocs del DVD El joc tradicional a Arbúcies. Fons MEMGA.

\section{El potencial educatiu del joc tradicional al segle XXI}

En aquest programa, s'hi ha fet palès l'interès $i$ la necessitat d'emprar el joc tradicional a les aules, tot aprofitant-ne la multifuncionalitat i la transversalitat com a metodologia d'ensenyament-aprenetatge de continguts i valors, des de qualsevol àrea. Les diferents aportacions de professionals de l'educació ens han demostrat el potencial del joc com a eina d'integració de joves nouvinguts, com a recurs per donar a conèixer als nens el patrimoni cultural proper - històric, arquitectònic, festiu, musical, etc.-, com a mètode per apropar els alumnes a la identitat cultural pròpia, com una via de mediació de conflictes en l'àmbit escolar, etc. També s'ha evidenciat la importància de posar a l'abast dels docents i futurs docents accions de formació explícita sobre jocs tradicionals, tant pel que fa al coneixement de la pròpia dinàmica dels jocs — com jugar-hicom pel que fa a quin aprofitament educatiu se'n pot treure - per què jugar-hi.

En una època com l'actual, marcada pels jocs electrònics, pensats per a jugar molt sovint de forma estàtica i individual, seria interessant veu- re com aquests jocs poden interactuar amb els tradicionals, que habitualment se centren més en l'aspecte comunicatiu i s'han de practicar a l'aire lliure. Aquest reptes s'han plantejat a la congrés de cloenda del programa "Els jocs en la història".

$\mathrm{Al}$ maig de 2012 ha tingut lloc a Móra la Nova i Ascó el congrés internacional "Els jocs en la història”. En aquesta darrera edició s'ha donat una dimensió internacional al tema, s'ha aprofundit en les temàtiques abordades en les jornades anteriors i s'han analitzant especialment els jocs del segle xxi: la indústria del videojoc, l'aplicació avui del joc tradicional en el procés d'aprenentatge en les diverses etapes educatives, la conjugació del trinomi jocs tradicionals, noves tecnologies i educació, etc. Aquest trinomi ha donat peu a un dels àmbits temàtics del congrés i a la seva taula rodona. En aquest àmbit s'han presentat treballs que aborden el paper de joc a l'escola en la resolució de conflictes (Unai Sáez, INEFC) i en l'educació en competències emocionals (Pere Lavega, INEFC); s'han explicat programes amb anys d'experiència en escoles com el Rodajoc (Grup de Mestres d'Educació Física de Ciutat Vella, Barcelona), que atén la integració d'alumnes de diverses cultures al Cicle Mitjà de Primària; els materials educatius publicats pel Seminari de Formadors en Educació Física de les Terres de l'Ebre o la presentació d'un nou joc esportiu inclusiu de pilota creat per Juanjo Biendicho (CEFIRE de Sagunt), el Colpbol.

Actes de les jornades "Recerca i patrimoni etnològic" i "Els jocs en la història"

Espuny, Elena (coord.) (2007): Recerca i patrimoni etnologic. Els jocs tradicionals. Institut Ramon Muntaner. Móra la Nova.

EsPunY, Elena (coord.) (2008): Recerca i patrimoni etnologic. Els jocs tradicionals $i$ les noves tecnologies. Institut Ramon Muntaner. Móra la Nova.

VAquer, Pineda; Barrull, Carles (coord.) (2009): Els jocs en la història. Les societats a través del joc. Aeditors. El Perelló.

BArrull, Carles; Espuny, Elena (coord) (2010): Els jocs en la història. Espais de joc: patrimoni, turisme i festa. Aeditors. El Perelló. 
BARrull, Carles; Espuny, Elena (coord) (2011): Els jocs en la història. Cultura material i immaterial en el joc. Aeditors. El Perelló.

BARRUll, Carles; EsPunY, Elena (coord) (2012): Els jocs en la història. Els jocs i la interculturalitat. Institut Ramon Muntaner. Móra la Nova.

Alguns recursos educatius disponibles sobre jocs tradicionals

Reculls de jocs publicats

BARDAJÍ, Francesca (2006): Jocs populars tradicionals a la comarca de l'Urgell. Tàrrega. Ajuntament de Tàrrega.

Busqué, Montserrat i PuJol, M. Antònia (1996): XIMIC, jocs tradicionals, Berga : Centre d'Estudis Musicals del Berguedà "L'Espill" : Amalgama.

Costes, Antoni (1997): Emborrapà!. Jocs de carrer jugats a Amposta. Ajuntament d'Amposta.

Lavega, Pere i Rovira, Glòria (2003): Els jocs tradicionals al Pallars Sobirà. Tremp. Garsineu.

La Riuada. Revista d'informació cultural. "Els jocs d'ahir". Núm 28, desembre de 2006. Associació Cultural “La Riuada”, Móra d'Ebre.

SANs, Joan (2000). Recull de juguetes artesanals de les Illes Balears. Palma de Mallorca. Universitat de les Illes Balears (Antropologia de l'Educació; 3).

SAns, Joan (2007). Juga a fer juguetes. Palma de Mallorca: Institut d'Estudis Baleàrics; La Foradada.

\section{Exposicions itinerants}

Joc tradicional i educació. Cia de Jocs l'ANÒNIMA, Associació cultural.

Exposició "El joc entre la tradició i la modernitat. Una experiència en el context d'Horta de Sant Joan”. INEFC de Lleida i Associació Cultural Lo Llaüt d'Ascó.

De joc a joc. Jocs tradicionals de la Ribera d'Ebre. Associació Cultural "Lo Llaüt" d'Ascó.

Joan Ortí. La diversitat cultural en les manifestacions lúdiques del món. Unes activitats a pre- servar i protegir. Associació Cultural La Tella, Sant Mateu.

Tallers

Tallers de jocs romans. Némesis SSCL. Tarragona.

Tallers de construcció de joguets amb materials de la natura. Guies dels Ports, Arnes.

Tallers de bòlit. Associació de Dones d'Anglesola.

Tallers de fer ballar baldufes, baldufes gegants i virolets òptics. Associació Amics de la baldufa.

Tallers de jocs cantats i de jocs que utilitzen la música. M. Antònia Pujol.

Tallers de jocs tradicionals. Cia de Jocs l'ANÒNIMA, Associació Cultural.

Taller Juguem com jugaven les nenes $i$ els nens de Tarraco. Camp d'Aprenentatge de la Ciutat de Tarragona. Departament d'Ensenyament de la Generalitat de Catalunya.

Itinerari de carrer Els jocs tradicionals de Verdú. Museu de joguets i autòmats. Col-lecció Mayoral. Verdú.

Joc de rol per conèixer el romànic La pau i la treva de Deu. Consorci Paleontologia i Entorn de Coll de Nargó (l'Alt Urgell).

Tallers de jocs tradicionals del Pallars Sobirà. Ecomuseu de les Valls d'Àneu. Esterri d'Àneu.

Tallers per a aprendre els valors de l'esperanto. Museu de l'esperanto. Subirats.

\section{Materials educatius}

BAntulÀ, Jaume (2006): "La introducció dels jocs populars i tradicionals en l'educació escolar dels infants" Temps d'educacio, pàg. 235248.

Capdevila, Gemma (1999). Unitat didàctica de joc maonès. Menorca: Institut d'Estudis Menorquins Consell Insular de Menorca.

Pubill, Biel i RaduÀ, Josep Maria. El patrimoni de joc a joc. Els jocs en temps dels moriscos. Quadern didàctic. Ajuntament d'Ascó.

Tort, Núria. El joc tradicional al rodal d' Arbúcies. DVD interactiu. Museu Etnològic del Montseny. Arbúcies. 
Treballs presentats 2006-2011 i publicats en les actes ${ }^{6}$

\begin{tabular}{|c|c|c|}
\hline Autor/a & Filiació & Títol de la intervenció \\
\hline Carme Queralt & Museu de les Terres de l'Ebre & $\begin{array}{l}\text { Iniciació al treball de camp en cultura } \\
\text { popular }\end{array}$ \\
\hline Pere Lavega i Biel Pubill & $\begin{array}{l}\text { Xè. Curs de Jocs Tradicionals } \\
\text { FESTCAT Horta St. Joan }\end{array}$ & $\begin{array}{l}\text { Projecte Europeu Cultura } 2000 \text { sobre jocs } \\
\text { tradicionals. }\end{array}$ \\
\hline Pere Lavega i Biel Pubill & INEFC Lleida i IES Flix & $\begin{array}{l}\text { La tecnologia al servei de la tradició: els jocs } \\
\text { tradicionals, entre la teoria i la pràctica }\end{array}$ \\
\hline $\begin{array}{l}\text { Núria Tort i Sandra } \\
\text { Pujadas }\end{array}$ & Museu Etnològic del Montseny & $\begin{array}{l}\text { El joc i el lleure tradicionals a Arbúcies } \\
(1900-1940)\end{array}$ \\
\hline Enrique Pedret & Club de Rem de Tortosa & $\begin{array}{l}\text { Recuperació de regates de festa major a } \\
\text { l'Ebre }\end{array}$ \\
\hline Pepa Nogués & Centre d'Estudis de la Terra Alta & Jocs tradicionals d'adults a la Terra Alta \\
\hline Jordi Serra & $\begin{array}{l}\text { Associació Cultural de } \\
\text { Montserrat }\end{array}$ & Ecologia del joc \\
\hline $\begin{array}{l}\text { Montsant Fonts i Salvador } \\
\text { Palomar }\end{array}$ & $\begin{array}{l}\text { Associació Cultural Carrutxa, } \\
\text { Reus }\end{array}$ & $\begin{array}{l}\text { Els jocs tradicionals al Priorat: recuperació } \\
\text { de joguines per treball de camp }\end{array}$ \\
\hline $\begin{array}{l}\text { Lourdes Rodríguez, Neus } \\
\text { Cortiella i Marta Prat }\end{array}$ & ZER Ports-Algars, la Terra Alta & Els jocs a les ermites de la Terra Alta \\
\hline Ramon Gallar & $\begin{array}{l}\text { Institut d'Estudis Comarcals del } \\
\text { Montsià, Amposta }\end{array}$ & $\begin{array}{l}\text { Recuperació de jocs tradicionals en l’àmbit } \\
\text { de l'Educació Primària.CEIP Soriano } \\
\text { Montagut. Amposta }\end{array}$ \\
\hline Àngel Gómez & $\begin{array}{l}\text { Escola Autonòmica de Jocs } \\
\text { Tradicionals de València. } \\
\text { Benissanó }\end{array}$ & La recerca. Començar per casualitat \\
\hline Xavier Roviró & $\begin{array}{l}\text { Grup de Recerca Folklòrica } \\
\text { d'Osona }\end{array}$ & $\begin{array}{l}\text { Memòria oral d'Osona: recull de jocs } \\
\text { populars tradicionals. }\end{array}$ \\
\hline Joaquim Buj & $\begin{array}{l}\text { Assoc. Cultural Lo Rafal. } \\
\text { Alcanar }\end{array}$ & $\begin{array}{l}\text { Recull de jocs tradicionals a l'escola: la Terra } \\
\text { Alta }\end{array}$ \\
\hline Carles Sancho & $\begin{array}{l}\text { Assoc. Cultural del Matarranya, } \\
\text { Calaceit }\end{array}$ & $\begin{array}{l}\text { Material didàctic sobre jocs populars i } \\
\text { tradicionals i dinamització del joc en català }\end{array}$ \\
\hline $\begin{array}{l}\text { Manel Serrabona i M.Pilar } \\
\text { Ares }\end{array}$ & IES Aran. Vielha & $\begin{array}{l}\text { Els jocs populars tradicionals a la Vall } \\
\text { d'Aran }\end{array}$ \\
\hline Francesca Bardají & $\begin{array}{l}\text { Museu Comarcal de l'Urgell- } \\
\text { Tàrrega }\end{array}$ & Jocs tradicionals a la comarca de l'Urgell \\
\hline Francesc Pasqual & Grup de Recerca de Cervelló & El joc de cucanya a Cervelló \\
\hline Pere Lavega i Biel Pubill & $\begin{array}{l}\text { INEFC Lleida i Associació } \\
\text { Cultural Lo Llaüt, Ascó }\end{array}$ & $\begin{array}{l}\text { Les noves tecnologies en l'aplicació dels jocs } \\
\text { tradicionals }\end{array}$ \\
\hline Jordi Tura i Núria Tort & $\begin{array}{l}\text { Museu Etnològic del Montseny. } \\
\text { Arbúcies }\end{array}$ & $\begin{array}{l}\text { El joc tradicional al rodal d'Arbúcies, un } \\
\text { DVD interactiu }\end{array}$ \\
\hline
\end{tabular}

6 Aquests treballs estan publicats en les actes de les jornades (<www.bestiari.net $>$ ). Les ponències i comunicacions presentades durant el Congrés Internacional Els jocs en la història el maig del 2012 estan actualment en procés de publicació. 


\begin{tabular}{|c|c|c|}
\hline $\begin{array}{l}\text { Victòria Almuni i Ferran } \\
\text { Grau }\end{array}$ & Diputació de Tarragona i URV & $\begin{array}{l}\text { REPTTE, un portal de recursos didàctics en } \\
\text { patrimoni a les comarques de Tarragona }\end{array}$ \\
\hline Biel Pubill & $\begin{array}{l}\text { IES Flix i Associació Cultural } \\
\text { "Lo Llaüt", Ascó }\end{array}$ & $\begin{array}{l}\text { El joc tradicional dins el projecte } \\
\text { "Comenius". Educació secundària. }\end{array}$ \\
\hline J. LL. Monjo i Ll. X. Flores & $\begin{array}{l}\text { Grup de recerca folklòrica } \\
\text { "Alacant" }\end{array}$ & $\begin{array}{l}\text { Passat, present i futur dels jocs tradicionals } \\
\text { a la comarca de la Marina. }\end{array}$ \\
\hline Jordi Pablo & $\begin{array}{l}\text { Arxiu Festiu Catalunya, } \\
\text { Barcelona }\end{array}$ & $\begin{array}{l}\text { Competència, atzar, simulacre i vertigen en } \\
\text { el joc }\end{array}$ \\
\hline Pepa Nogués & $\begin{array}{l}\text { Guies del Port i Parc Natural } \\
\text { dels Ports }\end{array}$ & $\begin{array}{l}\text { Educació ambiental amb la confecció de } \\
\text { joguets amb elements naturals }\end{array}$ \\
\hline Joan Launes & $\begin{array}{l}\text { Assoc. Cult. La Riuada, Móra } \\
\text { d'Ebre }\end{array}$ & Jocs tradicionals de la Ribera d’Ebre \\
\hline Rosa Canela & Fundació El Solà, la Fatarella & Jocs populars tradicionals al Maresme \\
\hline Joseba Etxebeste & Universitat del País Basc & $\begin{array}{l}\text { El procés de socialització a través dels jocs } \\
\text { infantils en el País Basc }\end{array}$ \\
\hline Gemma Capdevila & IES de Maó, Menorca & $\begin{array}{l}\text { El “Joc Maonés" i “Dins i fora”, dues } \\
\text { maneres de viure els jocs tradicionals }\end{array}$ \\
\hline Fernando Maestro & $\begin{array}{l}\text { Museo de Juegos Tradicionales } \\
\text { de Campo, Osca }\end{array}$ & Hablemos de ellas \\
\hline Pere Lavega i Biel Pubill & INEFC Lleida i IES de Flix & Jocs infantils i d'adults a Catalunya \\
\hline Francesca Bardají & $\begin{array}{l}\text { Museu Comarcal de l'Urgell- } \\
\text { Tàrrega }\end{array}$ & $\begin{array}{l}\text { Aspectes socials dels jocs tradicionals i } \\
\text { populars a la comarca de l'Urgell }\end{array}$ \\
\hline Axier Oiarbide & Universitat del País Basc & $\begin{array}{l}\text { El jokoa y el jolasa en el mundo adulto de } \\
\text { hoy }\end{array}$ \\
\hline Jaume Bantulà & Universitat Ramon Llull & $\begin{array}{l}\text { Els jocs tradicionals en la societat europea a } \\
\text { través de la filatèlia }\end{array}$ \\
\hline Joaquim Capdevila & Universitat de Lleida & $\begin{array}{l}\text { Els cóssos de la cordera. Ritual agrari, joc } \\
\text { rústic i esport atlètic }\end{array}$ \\
\hline Joan Armangué & $\begin{array}{l}\text { Universitat de Càller i Arxiu de } \\
\text { Tradicions de l'Alguer, Itàlia }\end{array}$ & El joc de la sortilla \\
\hline Albert Aragonés & $\begin{array}{l}\text { Assoc. Cultural "Lo CEL", } \\
\text { Alcanar }\end{array}$ & $\begin{array}{l}\text { Jocs tradicionals de Freginals recollits al } \\
\text { Diccionari català-valencià- balear }\end{array}$ \\
\hline Joan Ortí & $\begin{array}{l}\text { Associació Cultural "La Tella", } \\
\text { Sant Mateu }\end{array}$ & $\begin{array}{l}\text { Les jornades "El joc i la tradició" de St. } \\
\text { Mateu }\end{array}$ \\
\hline $\begin{array}{l}\text { Lourdes Rodríguez, Neus } \\
\text { Cortiella i Marta Prat }\end{array}$ & ZER Ports-Algars, la Terra Alta & $\begin{array}{l}\text { Experiència educativa: Fa molts anys també } \\
\text { es cantava i es jugava }\end{array}$ \\
\hline Jordi Salvadó & Assoc. Cultural "La mar d’amics" & Jocs tradicionals mariners de Palamós \\
\hline Carme Vergés & Museu Comarcal de Cervera & Cuit i amagar. La botiga dels joguets \\
\hline Guiseppe Giacon & $\begin{array}{l}\text { Associaciazione Giochi Antichi, } \\
\text { Itàlia }\end{array}$ & $\begin{array}{l}\text { Tocatí. El festival de juegos tradicionales } \\
\text { de Verona como elemento de promoción } \\
\text { territorial }\end{array}$ \\
\hline Jordi Ochoa & INEFC Lleida & $\begin{array}{l}\text { Jocs tradicionals en ermites, santuaris i } \\
\text { capelles de Catalunya }\end{array}$ \\
\hline
\end{tabular}




\begin{tabular}{|c|c|c|}
\hline Oriol Segarra & Ajuntament de Tortosa & $\begin{array}{l}\text { Patrimoni arquitectònic i jocs a la Festa del } \\
\text { Renaixement de Tortosa }\end{array}$ \\
\hline Pere Lavega i Biel Pubill & $\begin{array}{l}\text { INEFC Lleida i Associació } \\
\text { Cultural "Lo Llaüt", Ascó }\end{array}$ & $\begin{array}{l}\text { HORTAJOC!. Conèixer els espais d'Horta } \\
\text { de Sant Joan amb els jocs tradicionals }\end{array}$ \\
\hline Jordi Tortosa & Camp d'Aprenentatge Tarragona & $\begin{array}{l}\text { "Tarraco Viva”. Jugem com jugaven les } \\
\text { nenes i els nens de Tarraco }\end{array}$ \\
\hline Oriol Calvo & Museu del Càntir d'Argentona & $\begin{array}{l}\text { Els jocs tradicionals dins de la Festa del } \\
\text { Càntir d'Argentona }\end{array}$ \\
\hline Àngel Portet & $\begin{array}{l}\text { Associació Internacional de } \\
\text { Raiers, } \\
\text { la Pobla de Segur }\end{array}$ & $\begin{array}{l}\text { Raiers: de l’ofici tradicional a la Festa } \\
\text { d'Interès Nacional }\end{array}$ \\
\hline Francesca Bardají & $\begin{array}{l}\text { Museu Comarcal de l’Urgell- } \\
\text { Tàrrega }\end{array}$ & El joc del bòlit fa turisme \\
\hline $\begin{array}{l}\text { Paulo Coêlho de Araujo i } \\
\text { altres }\end{array}$ & $\begin{array}{l}\text { Universitat de Coimbra, } \\
\text { Portugal }\end{array}$ & $\begin{array}{l}\text { A Festa dos Tabuleiros, patrimonio cultural } \\
\text { das gentes de Tomar }\end{array}$ \\
\hline $\begin{array}{l}\text { Paulo Coêlho de Araujo i } \\
\text { altres }\end{array}$ & $\begin{array}{l}\text { Universitat de Coimbra, } \\
\text { Portugal }\end{array}$ & O Jogo da Péla na Praia da Tocha \\
\hline Oscar Garcia & $\begin{array}{l}\text { Fund. Victor Sallent i Assoc. } \\
\text { Cult. "La Bauma dels Encantats", } \\
\text { Berga }\end{array}$ & $\begin{array}{l}\text { Joc i festa: la Patum infantil de Berga. } \\
\text { Juguem a Patum. }\end{array}$ \\
\hline $\begin{array}{l}\text { Maria Feliu, Clara } \\
\text { Masriera i Anna Triadó }\end{array}$ & $\begin{array}{l}\text { Fundació Castell de Calafell- } \\
\text { Ciutadella Ibèrica de Calafell }\end{array}$ & $\begin{array}{l}\text { El joc, una eina per a aproximar-nos al } \\
\text { patrimoni arqueològic dels ibers }\end{array}$ \\
\hline Jordi Mayoral & $\begin{array}{l}\text { Museu dels joguets i els } \\
\text { autòmats. }\end{array}$ & Jocs tradicionals de Verdú \\
\hline Cristina Cardona & $\begin{array}{l}\text { Ajuntament de Mas de } \\
\text { Barberans }\end{array}$ & Artesania de la pauma: de treball a joc \\
\hline $\begin{array}{l}\text { Biel Pubill i Josep M. } \\
\text { Raduà }\end{array}$ & Assoc. Cultural “Lo Llaüt”, Ascó & $\begin{array}{l}\text { Les corrides de cavalls, rucs i matxos d'Ascó. } \\
\text { Joc, patrimoni i festa }\end{array}$ \\
\hline Raquel Codina & $\begin{array}{l}\text { Consorci Paleontologia i Entorn } \\
\text { de Coll de Nargó, Alt Urgell. }\end{array}$ & $\begin{array}{l}\text { La pau i la treva de Déu. Joc de rol en un } \\
\text { entorn romànic }\end{array}$ \\
\hline $\begin{array}{l}\text { Lourdes Rodríguez, Neus } \\
\text { Cortiella i Marta Prat }\end{array}$ & ZER Ports-Algars, Terra Alta & De festa en festa $i . .$. de joc en joc \\
\hline F. de la Torre i J. A. Hoyos & Federación Càntabra de Bolos & El projecte educatiu "Madera de ser" \\
\hline Fernando Maestro & $\begin{array}{l}\text { Museo de juegos tradicionales } \\
\text { de Campo, Osca. }\end{array}$ & $\begin{array}{l}\text { Jocs i esports tradicionals. Un llenguatge } \\
\text { comú a l'Europa actual. }\end{array}$ \\
\hline Joan Sanz Mercadal & Mestre d'Alaior, Menorca & $\begin{array}{l}\text { La importància de la jogueta en la } \\
\text { construcció de la persona }\end{array}$ \\
\hline Daniel Descomps & $\begin{array}{l}\text { Institut Universitari de Formació } \\
\text { de Mestres d'Aquitaine, França }\end{array}$ & Crear juguetes y nombrarlos en vivo \\
\hline Pere Lavega & INEFC Lleida & $\begin{array}{l}\text { La cultura immaterial en els jocs a través de } \\
\text { la història }\end{array}$ \\
\hline
\end{tabular}




\begin{tabular}{|c|c|c|}
\hline Roger Benito & $\begin{array}{l}\text { Institut d'Estudis Penedesencs, } \\
\text { Vilafranca del Penedès }\end{array}$ & Jocs i jugadors a la Barcelona baix medieva \\
\hline Jordi Abella & Ecomuseu de les Valls d'Àneu & $\begin{array}{l}\text { Recuperació de jocs tradicionals en el } \\
\text { desenvolupament de les Valls d'Àneu }\end{array}$ \\
\hline M. Antònia Pujol & UB i Aula de Musica Tradicional & Jocs que utilitzen la música \\
\hline Cris Molins & $\begin{array}{l}\text { Universitat Autònoma de } \\
\text { Barcelona }\end{array}$ & $\begin{array}{l}\text { El joc com a element inclusiu als patis } \\
\text { escolars de Catalunya }\end{array}$ \\
\hline Xavi Camino & $\begin{array}{l}\text { Antropòleg. Escola Superior de } \\
\text { Disseny Elisava }\end{array}$ & $\begin{array}{l}\text { El joc i l'esport com a oportunitats a l'espai } \\
\text { públic }\end{array}$ \\
\hline Raül Hernández & $\begin{array}{l}\text { Centre d'Estudis Històrics de } \\
\text { Terrassa i UAB }\end{array}$ & $\begin{array}{l}\text { Activitats ludicoesportives juvenils en els } \\
\text { espais públics }\end{array}$ \\
\hline Guillermo Soler & $\begin{array}{l}\text { Coordinadora de Colles } \\
\text { Castelleres de Catalunya }\end{array}$ & $\begin{array}{l}\text { El fet casteller i la integració de nouvinguts } \\
\text { a Catalunya }\end{array}$ \\
\hline Jaume Bantulà & Universitat Ramon Llull & $\begin{array}{l}\text { Aproximació a la cultura lúdica des d’una } \\
\text { perspectiva transcultural }\end{array}$ \\
\hline $\begin{array}{l}\text { Àngela Rosa Menages i } \\
\text { Joan Lluís Monjo }\end{array}$ & $\begin{array}{l}\text { Grup d'Estudis Folklòrics } \\
\text { Alacant }\end{array}$ & $\begin{array}{l}\text { Fava vinga!. Els jocs dels valencians } \\
\text { emigrats a Argèlia }\end{array}$ \\
\hline Abel Sensarrich & $\begin{array}{l}\text { Federació Catalana de Bitlles i } \\
\text { Bowling }\end{array}$ & $\begin{array}{l}\text { La implantació de les bitlles catalanes en } \\
\text { altres indrets del món }\end{array}$ \\
\hline $\begin{array}{l}\text { Alumnes de centres de } \\
\text { primària i de secundària } \\
\text { de Berga }\end{array}$ & Consell de la Infància de Berga & Els jocs de les diverses cultures de Berga \\
\hline Andrés Payà & Universitat de València & $\begin{array}{l}\text { El joc tradicional a la història de l'educació } \\
\text { social contemporània }\end{array}$ \\
\hline Maite Marín & Antropòloga & Del joc a la participació \\
\hline Miquel Giménez & Mestre de Terrassa. & De fora vingueren... \\
\hline Montse Piñeiro & Museu de l'Esperanto, Subirats & $\begin{array}{l}\text { El joc, un recurs en l'ensenyament i } \\
\text { transmissió dels valors de l'esperanto }\end{array}$ \\
\hline Biel Pubill & $\begin{array}{l}\text { IES de Flix i Associació Cultural } \\
\text { "Lo Llaüt", Ascó }\end{array}$ & $\begin{array}{l}\text { Potencialitats del joc com a recurs per a la } \\
\text { inclusió del nouvingut }\end{array}$ \\
\hline $\begin{array}{l}\text { Lourdes Rodriguez, } \\
\text { Ramon Codorniu i Neus } \\
\text { Cortiella }\end{array}$ & ZER Ports Algars, Terra Alta & $\begin{array}{l}\text { Arreu del món, també hi juguen?. Projecte } \\
\text { d'educació física a la ZER }\end{array}$ \\
\hline $\begin{array}{l}\text { Lourdes Rodriguez, } \\
\text { Ramon Codorniu i Neus } \\
\text { Cortiella }\end{array}$ & ZER Ports Algars, Terra Alta & $\begin{array}{l}\text { Compartim jocs, els d’aquí i els d’allà. } \\
\text { Projecte de jocs tradicionals }\end{array}$ \\
\hline Joan Ortí & $\begin{array}{l}\text { Universitat Jaume I i Associació } \\
\text { Cultural "La Tella", Sant Mateu }\end{array}$ & $\begin{array}{l}\text { Vincles interculturals de les manifesta } \\
\text { cions lúdiques d’arreu del món }\end{array}$ \\
\hline Maria Galizia & Educadora, Caldes de Montbui & La xerranca i la interculturalitat \\
\hline Montserrat Vidal & ZER Terra Alta Centre & Jocs tradicionals del món \\
\hline
\end{tabular}

